\title{
GLAAR: Geographic Location Aware Adaptive Routing in Mobile Ad Hoc Networks (MANETs)
}

\author{
Nisha Arora \\ Asst. Prof., IT Department, P.I.E.T. \\ Samalkha, Panipat \\ INDIA-132102
}

\author{
Ajay Jangra \\ Asst. Prof., CSE Department, U.I.E.T. \\ Kurukshetra University, Kurukshetra, \\ INDIA-136119
}

\begin{abstract}
Node Location information may reduce the overall communication overhead for packet forwarding in Mobile AdHoc Networks (MANETs). This paper proposes a novel Geographic Location Aware Adaptive Routing (GLAAR) protocol to reduce the computation and communication requirement for selection of next node (hop) for packet forwarding. Proposed protocol fetches the node location information using GPS and follows the robust, adaptive and efficient routing algorithm to ensure communication occurs with minimum no's of hops and computations.
\end{abstract}

Keywords: MANETs, LAR, GPS, node mobility, zonal routing.

\section{INTRODUCTION}

A mobile ad hoc network (MANETs) is a self-configuring, wireless, low range/power, mobile infrastructure less network where each participating node itself manages the communication over the network. For handling the communication among all nodes (mobile) routing protocols should be capable enough to handle mobility, scalability, and dynamicity of the nodes in mobile ad hoc network. Routing protocols may classify as Flat, Hierarchical and Geographical routing protocols. Flat routing may deploy as Proactive/Table driven protocol (routing information maintained in a table prior to transmission occurrence, eg. FSR, TORA, TBRPF etc.) and Reactive/ On-Demand protocols (manage the dynamic routing information with reduction in communication overhead eg. AODV, DSR etc.). [1] Hierarchical routing protocols organized the participating nodes in scalable group based efficient arrangements as in CGSR, ZRP, and LANMAR etc. Both of these routing approaches do not account for the location information of the mobile nodes as it accounted by Geographical routing mechanism in which GPS is responsible for conveying location information of each node present over the network. $[2,7]$ Using this physical location of the nodes routing overhead can be reduced and efficiency of routing protocols can be improved as in GPSR, LAR etc. In these protocols location information (obtain via GPS) is used for route discovery mechanism which ultimately reduces the search space and limit the flooding area and allows the routing of information over a refined path. [8]

\section{RELATED WORK}

This section describes some of the existing routing protocols that are used in mobile ad hoc network. Some of the directional based routing includes: LAR, GPSR, LABAR, and LAKER.

LAR (Location Aided routing) uses the location information to reduce routing overhead involved in flooding. LAR uses two schemes for routing: Scheme1 uses concept of zones that are request zone and expected zone. Before packet transmission it first calculates request zone over which packet is to be transmitted. If the node is in the request zone then it receives and forwards the packet otherwise discard the packet. The same procedure continues until expected zone is reached where destination node lies. Scheme2 is based on the estimation of distance from destination. The node having least relative position from destination is chosen to forward packet to its next neighbour until destination is reached. [3]

GPSR (Greedy perimeter stateless routing) is based on two principles: greedy forwarding and perimeter forwarding. In greedy forwarding it chooses the node that is lying closer to destination and forwards the packet via that node. When packet come to a dead end then it performs perimeter forwarding in which position using relative neighbourhood graph (RNG) is calculated and traversing is done using right hand rule. [4]

LABAR (Location Area Based Ad hoc Routing) routing protocol is based on virtual backbone formation which is used for representing position of nodes. G-node (root) initiates virtual backbone formation and tracks the information using GPS which later on helps in directional routing over the network. Source G-node instructs node of its zone for how to forward packet inside the zone. Each zonal node consults its G-node for best directionality instructions to forward packet to destination node. [5]

LAKER (Location Aided Knowledge Extraction Routing) uses cached guiding_routes which helps in assisting the route discovery process. In this protocol structure do not change rapidly. So it uses guiding locations from source to destination for easy transmission. LAKER request zone helps in reducing routing overhead involved during transmission. Guiding_route also helps in finding void areas present over the network. [6] Geographical protocols uses location information for traversing so these protocol calculate the position of each node using GPS [16,17] (Global positioning system) which requires use of GPS satellite and GPS receiver for communication and the whole process works as follows:

1) GPS receiver communicates with GPS satellite for calculating its position.

2) Receiver receives the message via satellites.

3) Using those signals position is then displayed in the form of latitude and longitude.

\section{PROBLEM STATEMENT PROPOSED SOLUTION}

In MANETs all nodes may keep on moving from its estimated position (destination node also) so it does not ensure the best shortest path coverage. It is unpredictable priory, in which direction destination node is going to move thus making it 
resistive to adaptability. Number of hops, computations and bandwidth consumption may also be reduced to make routing more efficient and saving node's time and power. This paper propose a novel protocol named as Geographic Location Aware Adaptive Routing (GLAAR) that is adaptable, efficient and robust enough to confirm for sure packet delivery to destination using lesser computation requirement even if destination node is mobile.

\section{GEOGRAPHIC LOCATION AWARE ADAPTIVE ROUTING (GLAAR) PROTOCOL for MANETs: The proposed model}

Geographic Location Aware Adaptive Routing (GLAAR) is purely based on geographical based routing and supports high level of node mobility, band-width efficiency, adaptive routing according to the movement of nodes and offer high reliability.

Before understanding the functionality of proposed routing protocol, we have to consider some prerequisite and data management table required for communication.

4.1 Pre-assumptions: Some of the pre assumptions related to GLAAR are elaborated below:

- Beacon header format

Whenever a node broadcast beacon_request/ beacon_reply, it contains fields in the format as described in figure 1 and 2: Type field describe request/reply for beacon message. Source Address contains address of source node and Destination Address contains destination node address. Field request contains request for the zonal information that provides information regarding Zone ID (ZID), Zone Incharge (ZI) and Zone Member (ZM) in beacon_reply.

\begin{tabular}{|c|c|c|l|}
\hline Type & $\begin{array}{c}\text { Source } \\
\text { Address }\end{array}$ & $\begin{array}{c}\text { Destination } \\
\text { Address }\end{array}$ & Field Request \\
\hline
\end{tabular}

Fig 1: Beacon_Request header

\begin{tabular}{|c|c|c|c|c|c|}
\hline Type & $\begin{array}{c}\text { Source } \\
\text { Address }\end{array}$ & $\begin{array}{c}\text { Destination } \\
\text { Address }\end{array}$ & ZID & ZI & ZM \\
\hline
\end{tabular}

Fig 2: Beacon_Reply header

\section{Table Formation}

GLAAR maintains three tables for storing information regarding nodes present in a zone. Neighbour Node Awareness Table (NNAT): Intra-zone stores information regarding all nodes present with in a zone. It contains fields such as Zone ID (ZID), Zone Incharge (ZI), Zone Members (ZM), Reliabilty factors such as existence time, and battery life of a node help in deciding ZI of a zone which is decided on the basis of node having highest value among all nodes present within a zone as shown in table 1 (threshold value-55) using figure 3.

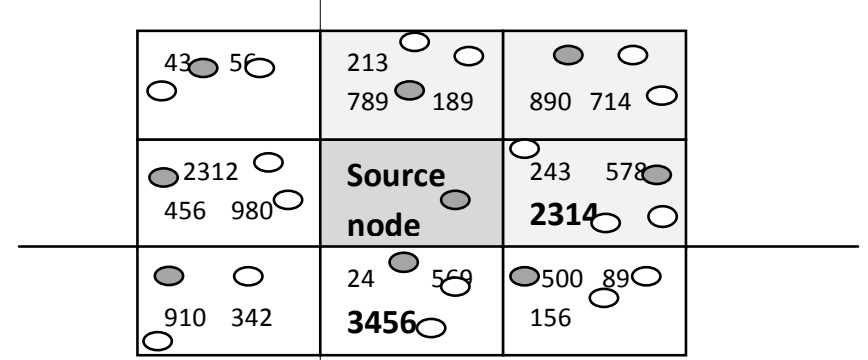

Fig 3: Source node surrounded by its 8 neighbour zones
Table 1. Neighbour node Awareness Table (NNAT): Intra-zone

\begin{tabular}{|c|c|c|c|c|}
\hline ZID & ZI & $\mathbf{Z M}$ & $\begin{array}{c}\text { Existence } \\
\text { time (\%) }\end{array}$ & $\begin{array}{c}\text { Battery } \\
(\mathbf{\%})\end{array}$ \\
\hline 3001 & 43 & 45,56 & 75 & 78 \\
\hline 4060 & 789 & 213,189 & 79 & 78 \\
\hline 3560 & 890 & 4,714 & 63 & 86 \\
\hline 2314 & 578 & $5,115,243$ & 72 & 84 \\
\hline 6790 & 500 & 89,156 & 64 & 76 \\
\hline 3456 & 24 & 569,450 & 68 & 77 \\
\hline 4565 & 910 & 59,342 & 62 & 76 \\
\hline 2345 & 456 & 2312,980 & 76 & 85 \\
\hline
\end{tabular}

Another table is Neighbour Node Awareness Table (NNAT): Inter-zone that stores fields such as ZID, ZI present neighbour to requesting zone as shown in table 2. Neighbour Zone Awareness Table (NZAT) contains information regarding three zones that lie towards the direction of destination and are chosen for further transmission (among A, B and C-zone) is always stored in NZAT as shown in table 3.

Table 2. Neighbour node Awareness Table (NNAT): Inter-zone

\begin{tabular}{|c|c|}
\hline $\begin{array}{c}\text { Zone ID } \\
(\text { ZID })\end{array}$ & Zone Incharge (ZI) \\
\hline 3001 & 43 \\
\hline 4060 & 789 \\
\hline 3560 & 890 \\
\hline 2314 & 578 \\
\hline 6790 & 500 \\
\hline 3456 & 24 \\
\hline 4565 & 342 \\
\hline 2345 & 456 \\
\hline
\end{tabular}

Table 3. Neighbour Zone Awareness Table (NZAT)

\begin{tabular}{|c|c|c|}
\hline $\begin{array}{c}\text { Zone Number } \\
(\mathrm{ZN})\end{array}$ & $\begin{array}{c}\text { Zone Incharge } \\
(\mathrm{ZI})\end{array}$ & $\begin{array}{c}\text { Zone Members } \\
(\mathrm{ZM})\end{array}$ \\
\hline 4060 & 789 & 189,213 \\
\hline 3560 & 890 & 714,4 \\
\hline 2314 & 578 & $243,115,5$ \\
\hline
\end{tabular}

- Each node present over the network has GPS receiver attached to it

Every node has GPS receiver for determining its own position and destination position and directionality for packet forwarding is determined using destination node position (helps in deciding in which quadrant to move further). 


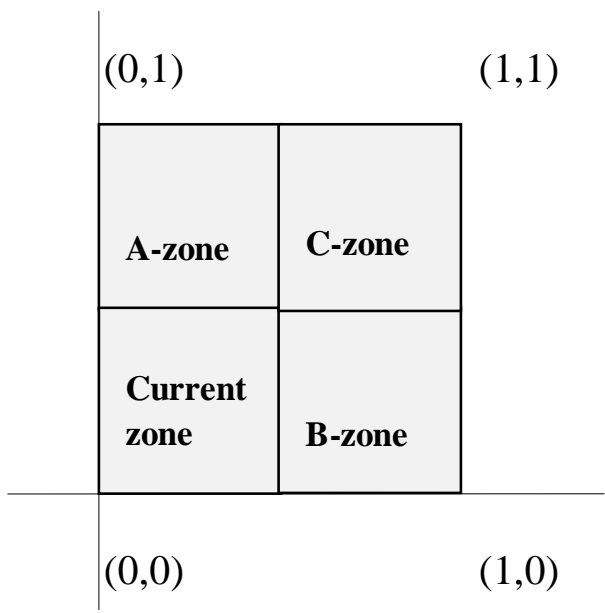

Fig 4: Current Zone surrounded by three zones

- Each current transmission node is covered by three zonal areas

For further transmission of packets over the zones, it is always decided among its surrounding three zones only as shown in figure 4 . Zone where current zone node lies is named as Current zone with coordinates as $(0,0)$, the zone lying above it with coordinates $(0,1)$ as $A$-zone, the zone lying right to A-zone with coordinates $(1,1)$ as $C$-zone and the zone lying below $\mathrm{C}$-zone with coordinates $(1,0)$ as $B$-zone.

\subsection{Algorithm}

\section{ALGO I: Updating NZAT and NNAT tables}

1) Current_ZI sends beacon message for creating table. // Current_ZI is zone incharge of current zone

2) Neighbour zone ZI node sends beacon_reply.

3) Current_ZI stores information of zones required for further packet transmission.

4) Tables NZAT, NNAT (intra-zone) and NNAT (inter-zone) are updated.

ALGO II: Packet forwarding

1) Current_ZI estimates position and directionality of destination_node using GPS and position itself in the quadrant which lie towards the directionality of destination starting from $(0,0)$.

2) Current_ZI update table using ALGO I

3) If destination is present in NZAT \{ then

forward packet to destination_ZI which then forward it to destination and send ACK to Current_ZI and exit

4) Else \{

Compare distance of three zones ZI from destination Select ZI having least distance from destination and forward packet to it

Send ACK to Current ZI

Mark incharge of zones having least distance from destination as Current_ZI and zone as Current_zone \}

5) End if

6) Repeat steps 2 to 5 while destination is not reached

\subsection{Working of GLAAR}

Source node notifies its position as well as destination position and directionality for packet forwarding using GPS and initialize routing by selecting quadrant that lie towards the direction of destination with initial position at $(0,0)$. Then Current_ZI sends beacon_message and its neighbours respond to it by sending information regarding the complete zone to update NZAT and NNAT table. These tables contain the information regarding all neighbour nodes and three special zones (A-zone, B-zone, C-zone) which lie towards the direction of destination. Among those zones, it compares for the node having least distance to destination (i.e. whose ZI distance to destination is shorter). Least distance ZI is chosen as next forwarding node and Current_ZI transmit packet to that node (current forwarding node) and provide ACK for the same. Then that node is declared as Current_ZI and zone as Current-zone from where further communication proceeds in the same manner until packet is delivered to destination node.

\section{EFFICIENCY ANALYSIS OF GLAAR}

For transmission of packets, destination node may shift its position thus being part of some new zone. For that there may arise three scenarios during transmission that are destination node remain in same zone, destination node moves away or towards the source zone. Case study for these three cases is discussed below:

Scenario I: When destination node remains in the same zone

Source node is positioned in the Zone Number (ZN) 201 and destination in Zone Number (ZN) 405. There may arises case when during transmission of packets destination node shifts its position but still remains in the same zone. In this case GLAAR protocol works as shown in figure 5. The changed position (still in same zone shown in red and earlier position in yellow) of destination can be tracked using GPS. The process of transmission of packets to destination node occurs in the same manner.

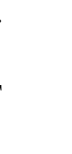

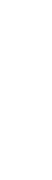

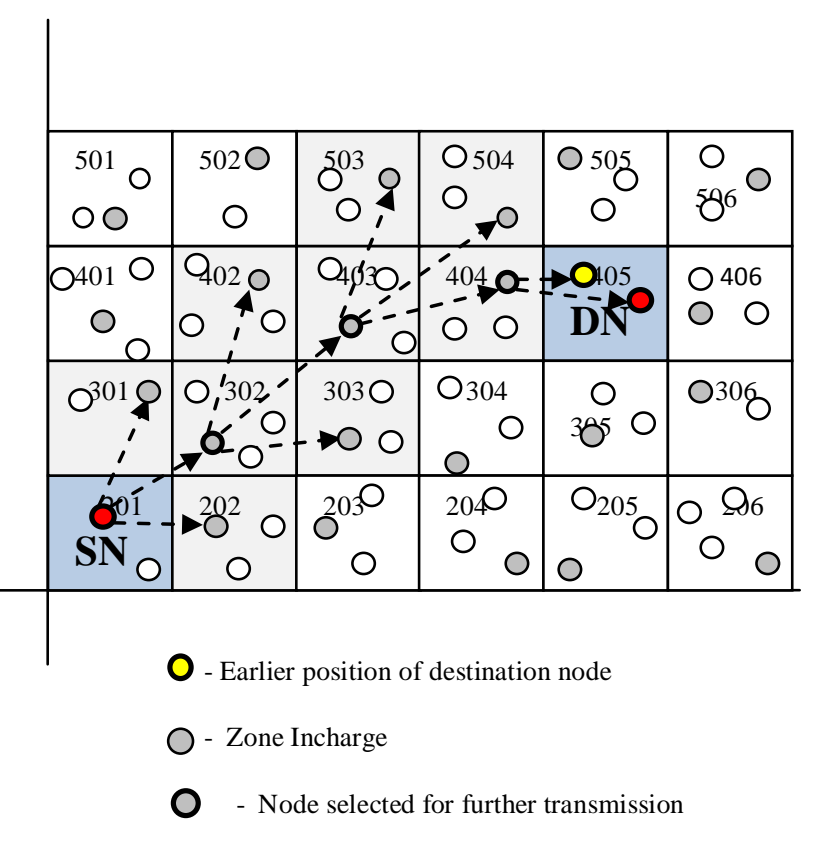

Fig 5: When destination node remains in the same zone 
Scenario II: When destination node moves towards source node

As shown in figure 6, Source node lies in Zone Number (ZN) 201 and destination in Zone Number (ZN) 405. Later during transmission destination position may move towards source node and let us assume that new destination node position may lie in $\mathrm{ZN} 304$. GLAAR is also adaptable to that case being aware of the changed destination position. In this case, number of hops to be travelled can be reduced thus improving the efficiency and saves node time and power.

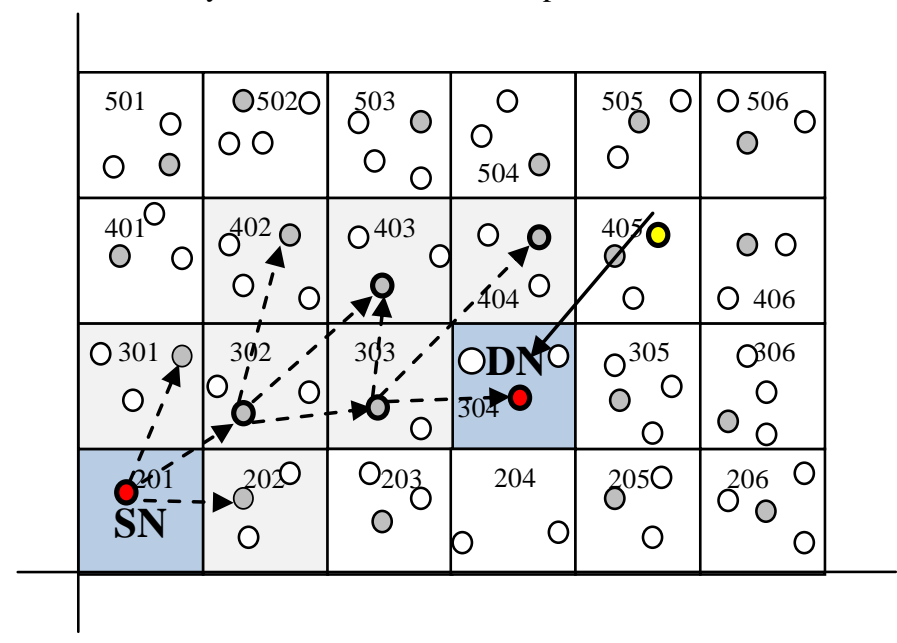

SN-Source node
DN- Destination node
O - Earlier position of destination node
O - Zone Incharge
- Node selected for further transmission

Fig 6: When destination node moves towards source node Scenario III: When destination node moves away from source node

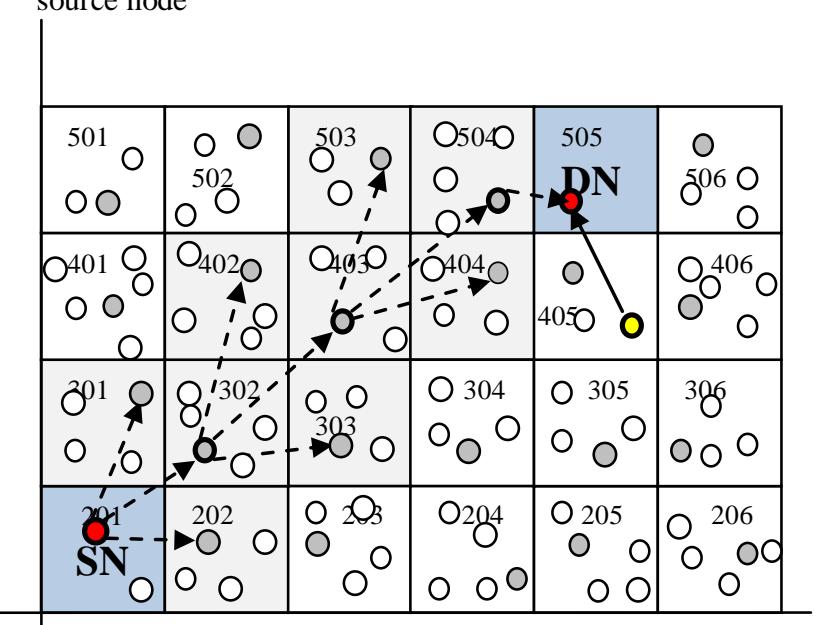

SN-Source node
DN- Destination node
O - Earlier position of destination node
O - Zone Incharge
- Node selected for further transmission

Fig 7: When source node moves away from destination
As shown in figure 7, Source node lies in Zone Number (ZN) 201 and destination in Zone Number (ZN) 405. Being a mobile node, destination node may join another zone. Let us assume that destination node now lie ZN 505 leaving ZN 405, thus moving away from source node. In that case number of hops increases depending upon the newer position of destination node but still saving retransmission requirement which ultimately save additional use of resources such as battery power and time.

From above discussed scenarios, it is analyzed that GLAAR protocol makes bandwidth-efficient packet forwarding rather than flooding packets over the network and less-computations are required for selection of next node for packet forwarding.

\section{PERFORMANCE EVALUATION}

The performance analysis of GLAAR is done using Network Simulator-2 or NS-2 which is a discrete event network simulator. NS-2 is mainly used for the simulation of routing and multicast protocols and is heavily used in ad hoc networking research. We evaluate performance of GLAAR by analyzing throughput of sending and receiving packet and jitter effect of packets sent and received over the network.

\subsection{Simulation Scenario}

Following are the configuration parameters that are chosen for performing simulation are shown in table 4:

Table 4. Simulation Parameters

\begin{tabular}{|c|l|}
\hline PARAMETER & VALUE \\
\hline Movement Model & Random Multihop \\
\hline MAC Layer & Mac/802_11 \\
\hline Interface Queue Type & Queue/DropTail/PriQueue \\
\hline $\begin{array}{c}\text { Link Layer Protocol } \\
\text { Number of Mobile }\end{array}$ & 05 \\
\hline Routing Protocol & AODV+GLAAR \\
\hline $\begin{array}{c}\text { Simulation Area } \\
\text { Simulation Time }\end{array}$ & $500 * 400$ \\
\hline $\begin{array}{c}\text { Maximum Packets in } \\
\text { Interface Queue }\end{array}$ & 50 \\
\hline
\end{tabular}

\subsection{Simulation Results}

Simulation analysis of GLAAR for 05 nodes is shown using graphs for throughput and jitter effect analysis.

Network throughput is the total number of packets that reach their destination over the total number of packets sent by the source or we can say throughput is the number of packets sent per unit TIL (TIL is the Time Interval Length).

Figure 8 shows the throughput of sending packet (No. of packets/TIL) over simulation time $(50$ to $150 \mathrm{sec})$. Throughput of sending packets/TIL goes on with little variation and increases abruptly in simulation time of 60 to 70 sec. For the rest it continues to give nearly a consistent throughput of 160-170 packets for GLAAR. So for GLAAR 
no of packets/TIL shows consistent variation, thus making it efficient in terms of transmission.

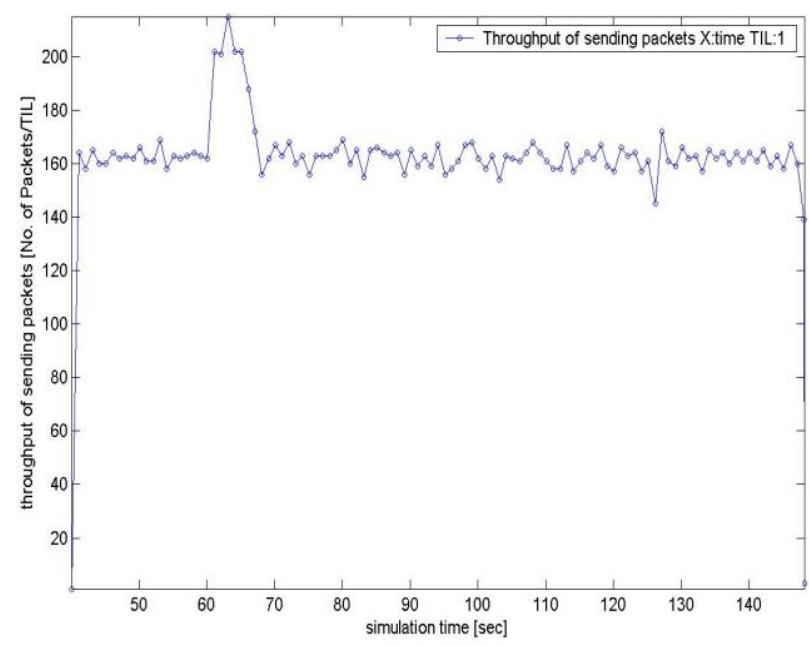

Fig 8: Throughput of sending packets v/s simulation time

The simulation result of throughput analysis of receiving no. of packets/TIL over simulation time (50 to $150 \mathrm{sec}$ ) is shown below in figure 9 . Initially for the simulation time $0-62 \mathrm{sec}$, it shows little variation and shows the throughput of nearly 80 packets/TIL. Under simulation time of 65-130 no. of packets/TIL received increases, thus showing GLAAR efficiency in terms of scalability for no. of packets received. Afterwards it decreases drastically.

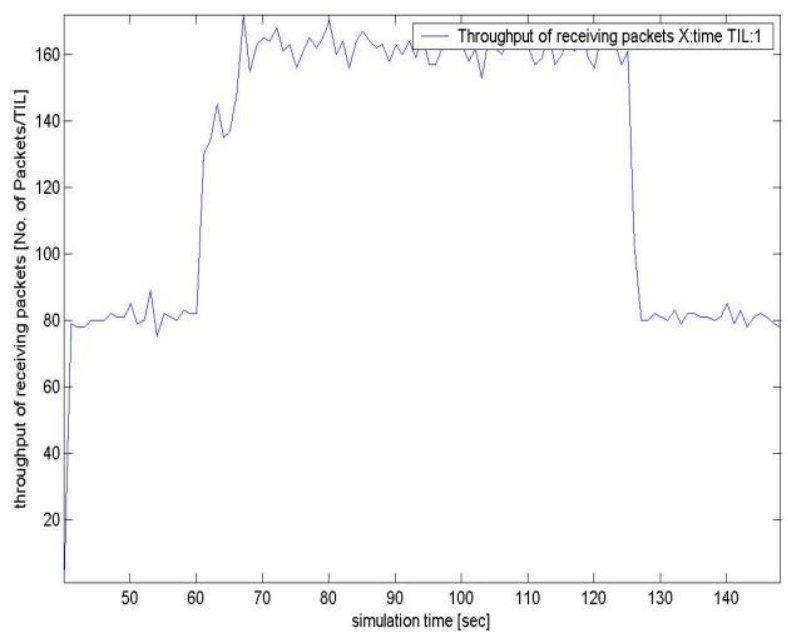

Fig 9: Throughput of receiving packets v/s simulation time

Figure 10 shows the jitter effect of sent packets over the network as a function of sequence number. Jitter is often used as a measure of the variability over time of the packet latency across a network. Jitter remains almost constant throughout the entire operation for sent packets over the network. Initially the jitter is $0.01 \mathrm{sec}$, remains almost constant.

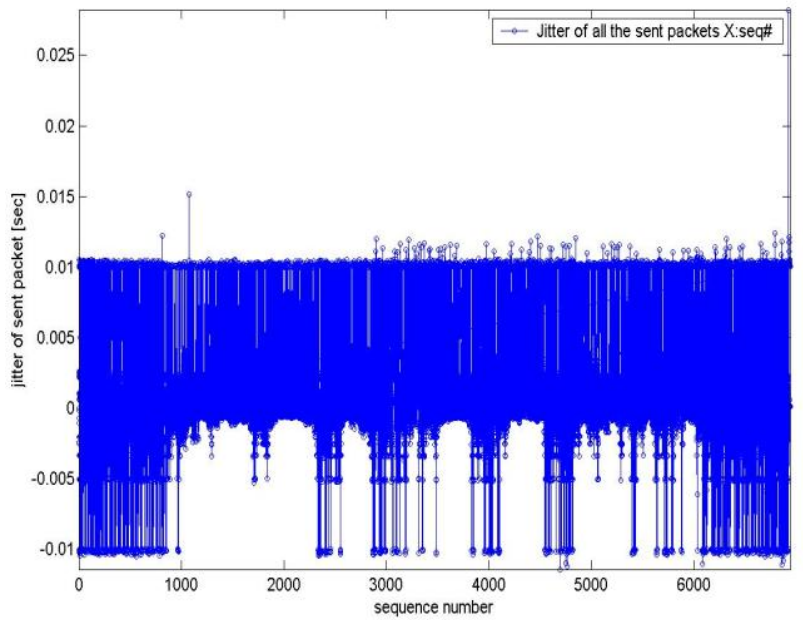

Fig 10: Jitter effect of sending packets v/s sequence number

Jitter effect for received packet as shown in figure 11, is high initially but later on goes low and remains constant afterwards up to sequence number 6000 and shows little higher variations for above sequence number. Hence from the above simulation we conclude that evaluation of GLAAR meet the requirement and make it efficient in terms of bandwidth, scalability, and throughput and tolerable to jitter effect.

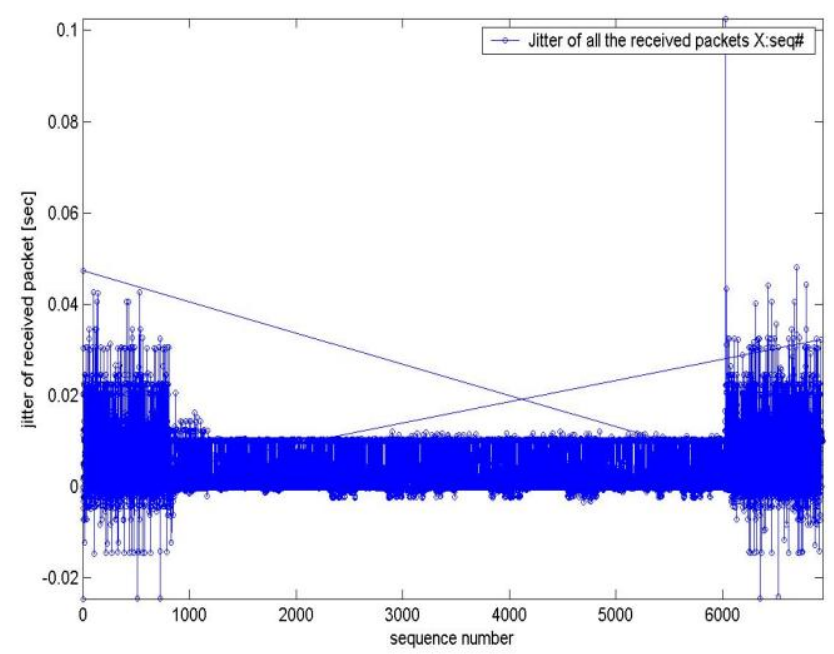

Fig 11: Jitter effect of sending packets v/s sequence number

\section{CONCLUSION}

Geographic routing can reduce routing overhead involved in packet transmission and this paper presents a novel Geographic Location Aware Adaptive Routing (GLAAR) Protocol, which is adaptive, reliable, and efficient in terms of path selection for packet forwarding. GLAAR is adaptable to the moving destination whether destination node moves towards/ or away from the source node as shown using different case scenarios, thus it imparts efficiency in terms of 
route discovery, bandwidth utilization and resource usage. Simulation results enhance the performance analysis of GLAAR in terms of throughput and jitter tolerance for the packet transmission over the network.

\section{REFERENCES}

[1] Ajay Jangra, Nisha Arora, "Routing Techniques in Mobile Ad-hoc Networks (MANETs): An Analytical Review and Concerned Challenges", IJCST, Vol. 3, Issue. 2, Apr-Jun 2012

[2] M.Mauve, J. Widmer and H. Hartenstein, "A Survey on Position- based Routing in Mobile Ad Hoc Networks" IEEE Network Magazine, 15(6): 30-39, Nov 2001.

[3] Young B. Ko, Nitin H. Vaidya, "Location-aided Routing (LAR) in mobile ad hoc networks", ACM/Baltzer Wireless networks (WINET), Vol. 6-4 pp 307-321 2000.

[4] Brad Karp. H.T. Kung, "GPSR: Greedy Perimeter Stateless Routing for Wireless networks", Proc. ACM MobiCom 2000.

[5] Gergely et.al, "LABAR: Location Area Based Ad Hoc Routing for GPS-Scarce Wide-Area Ad Hoc Networks", IEEE Computer Society, 2003.

[6] Jian Li, Prasant Mohapatra, "LAKER: Location Aided Knowledge Extraction Routing for Mobile Ad Hoc Networks", Proc. IEEE Wireless Comm. and Networking Conf. (WCNC '03), 2003.

[7] Ljubica Blazevic et.al , "A Location-Based Routing Method for Mobile Ad Hoc Networks", IEEE Transactions on Mobile Computing, Vol. 3, NO. 4, OctDec 2004.
[8] Vasil Hnatyshin et.al, "A Comparative Study of Location Aided Routing Protocols for MANET",

[9] S.M. Das, H. Pucha, Y.C. Hu, "Performance Comparison of Scalable Location Services for Geographic Ad Hoc Routing", IEEE INFOCOM 2005

[10] Jinyang Li et.al "A Scalable Location Service for Geographic Ad Hoc Routing"

[11] Xiaojing Xiang, Zehua Zhou, Xin Wang, "Robust and Scalable Geographic Multicast Protocol for Mobile Ad hoc Networks", IEEE INFOCOM, 2007.

[12] Erik Kuiper, Simin, "Geographical Routing with Location Service in Intermittently Connected MANETs", IEEE 2010.

[13] T. Spyropoulos et.al, "Efficient Routing in Intermittently Connected Mobile Networks: The Single-Copy Case", IEEE/ACM Trans. On Networking, vol. 16, no. 1, pp. 63-76, 2008.

[14] T. Camp, J. Boleng and L. Wilcox, "Location Information Services in Mobile Ad Hoc Networks", Proc. IEEE Int. Conf. Commun., 2002, pp. 3318-3324.

[15] Priyanka, Komal Kumar Bhatia, Ajay Jangra, "FRENSA: Farthest, Reliable and Efficient Node Selection Algorithm for Mobile Ad-hoc Networks (MANETs)" IJCST Vol. 1, Issue 2, December 2010.

[16] NAVSTAR GPS operations, available via WWW at URL: http://tycho.usno.navy.mil/gpsinfo.html.

[17] B.W. Parkinson and S.W. Gilbert, NAVSTAR: global positioning system - ten years later, Proceedings of the IEEE 71(10) (1983). 